\title{
Phase angle associated with over-hydration in healthy Chinese
}

Chai Yuanmin ${ }^{1 \dagger}$, Li Jing ${ }^{2 \dagger}$, Sun Xiuli ${ }^{3}$, Lei Zhenkun ${ }^{3}$, Zhang Lirong ${ }^{1}$ and Hou Guocun ${ }^{3 *}$

${ }^{1}$ Inner Mongolia Medical University, Hottot, 010110, China

${ }^{2}$ Division of Neurology, BaoTou Central Hospital, BaoTou, 014040, China

${ }^{3}$ Division of Nephrology, BaoTou Central Hospital, BaoTou, 014040, China

*Corresponding author: Hou Guocun, email: houguocun2007@163.com, telephone: +086-13848249140

$\dagger$ These authors contributed equally to this work

Author Contributions: Hou Guocun and Sun Xiuli conceived and designed the study; Chai Yuanmin, Li Jing and Zhang Lirong performed the study; Chai Yuanmin and Lei Zhenkun collected the data; Hou Guocun, Li Jing and Chai Yuanmin analyzed the data; Chai Yuanmin, Li Jing and Hou Guocun wrote the paper.

Conflicts of Interest: The authors declare no conflict of interest.

\section{Abstract}

Background A body composition monitor (BCM) has a role not only in determining over-hydration (OH) but also as an aid to nutritional assessment. For dialysis patient-specific clinical applications of BCM, it is necessary to clarify the relationship between body composition parameters and $\mathrm{OH}$ in healthy Chinese individuals. Methods This cross-sectional study involved 314 healthy individuals with a mean age of $45.7 \pm 13.1$ years. BCM measurements were performed while the subjects were fasting. Results The mean $\mathrm{OH}$ level was $0.379 \pm 0.81 \mathrm{~L}$. Lean tissue index (LTI) and Lean tissue mass (LTM) were significantly higher in males $(p<0.001)$, while fat tissue index (FTI) was significantly higher in females $(p<0.001)$. In univariate correlation analysis, FTI, Fat, and ATM had a negative correlation with $\mathrm{OH}$ in females and all subjects $(p<0.05)$, while LTM and BCM had a positive correlation in all subjects $(p<0.05)$. There was a significant negative correlation between phase angle $(\mathrm{PhA})$ and $\mathrm{OH}$ in males, females, and all subjects $(\mathrm{r}=-0.634, p<0.001 ; \mathrm{r}=-0.666, \mathrm{p}<0.001 ; \mathrm{r}=-0.484, p<0.001$, respectively). In multivariate linear regression analysis, PhA $(\beta=-1.266, p<0.001)$, LTM $(\beta=0.987, p<0.001)$, age $(\beta=-0.307$, $p<0.001$ ) were independent predictors of $\mathrm{OH}$. Conclusions This study demonstrated that age, LTM and especially $\mathrm{PhA}$, had important roles in predicting $\mathrm{OH}$ in healthy Chinese individuals. In the future, PhA may aid in clinical assessment by helping to titrate dry weight among hemodialysis patients with malnutrition.

Keywords: bio-impedance, phase angle, over-hydration, body composition, nutrition, hemodialysis

\section{Introduction}

Fluid abnormalities are commonly observed during maintenance hemodialysis (MHD) in end stage renal disease patients. Chronic volume overload can induce hypertension, left ventricular hypertrophy, heart failure, and pulmonary edema. ${ }^{[1,2]}$ In contrast, chronic volume deficits can induce intradialytic hypotension, muscle cramps, and shock. ${ }^{[3,4]}$ Management of fluid volume in MHD patients, especially in malnourished individuals, has been a challenge to nephrologists. However, objective methods that evaluate fluid status are limited in clinical practice. In recent years, body composition monitoring $(\mathrm{BCM})$ based on bioimpedance spectroscopy has been used to identify excess fluid retention and to help with nutritional assessments. It has been increasingly applied in dialysis facilities worldwide..$^{[5-7]}$

Even so, simple reliance on over-hydration $(\mathrm{OH})$ obtained from $\mathrm{BCM}$ while ignoring the interaction of other factors may lead to inappropriate management decisions. Although fluid volume varied substantially by age, sex 
and body composition, there were few studies investigating the role of body composition, including phase angle $(\mathrm{PhA})$ in healthy individuals or MHD patients. For patient-specific clinical applications of BCM, it will be necessary to clarify the relationship between the parameters of body composition and $\mathrm{OH}$. In this study, we began to explore those relationships in healthy Chinese individuals.

\section{Subjects and methods}

\subsection{Subjects}

A total of 314 healthy subjects from the local community who were patients at the Physical Examination Centre of the Baotou Central Hospital were enrolled beween 25 Jul 2018 and 24 Oco 2018(165 female and 149 male; All the induviduals are Han Chinese). They had a mean age of $45.7 \pm 13.1$ years). Individuals were eligible for inclusion if they were older than 18 years of age and had routine screening tests including fasting blood glucose (FBG), hepatic and renal function tests, and a urinalysis, that all were within normal limits. Those with a history of cerebral infarction, acute myocardial infarction, renal failure, diabetes, rheumatoid arthritis, visible edema, metallic implants, implanted cardiac pacemakers, major amputations of the extremities, HIV infection, or current pregnancy were excluded from this study. All the participants gave their written informed consent prior to enrollment as subjects in the study. This study was approved by the Baotou Central Hospital Clinical Research Ethics Committee.The ethical approval number was [2018 (ethics) 007].

\subsection{Methods}

We used a validated multi-frequency bioimpedance spectroscopy device (Body Composition Monitor [BCM], Fresenius Medical Care, Germany) in healthy subjects as previously reported. Briefly, electrodes were attached to one hand and one foot with the individual in the supine position. In essence, BCM estimates electrical resistance by applying alternating current at 50 different frequencies over a range of 5 to $1000 \mathrm{kHz}$. Parameters obtained directly through BCM were extracellular water (ECW), intracellular water (ICW), total body water (TBW), overhydration $(\mathrm{OH})$, and the ECW to ICW ratio (E/I), which reflects the fluid balance. Lean tissue mass (LTM), LTI (obtained by dividing LTM by height squared), lipid mass (Fat), adipose tissue mass (ATM), fat tissue index (FTI; calculated by dividing ATM by height squared), body cell mass (BCM), and phase angle (PhA) were used as markers for a nutritional status. BCM measurements were performed in fasting subjects the morning after their blood samples were collected.

\subsection{Statistical analysis}

All continuous variables were expressed as mean \pm standard deviation (SD). Comparisons between males and females were made using independent $t$-tests after confirmation of normal distributions for all variables. Pearson's correlation analysis was used to examine correlations between $\mathrm{OH}$ and other variables. To assess independent variables associated with $\mathrm{OH}$, we performed multiple linear regression analysis when differences in the variables were significant in the univariate analysis. $P$-values $<0.05$ were considered statistically significant for all calculations. Statistical analysis were performed using SPSS for Windows version 19.0 (IBM Corp., Armonk, NY, USA).

\section{Results}

\section{1 Individual Characteristics}

Figure 1 showed a histogram of $\mathrm{OH}$ in healthy subjects. The mean $\mathrm{OH}$ level was $0.379 \pm 0.81 \mathrm{~L}$. Male subjects had significantly higher levels of $\mathrm{OH}$ than females $(0.505 \pm 0.89$ versus $0.266 \pm 0.71 \mathrm{~L}, t=2.692, p=0.007)$. A total of $247(78.7 \%)$ of the 314 subjects had values that were equivalent to the standard value of healthy Caucasian subjects that have been reported in foreign countries $(-1.1$ to $1.1 \mathrm{~L})$. 


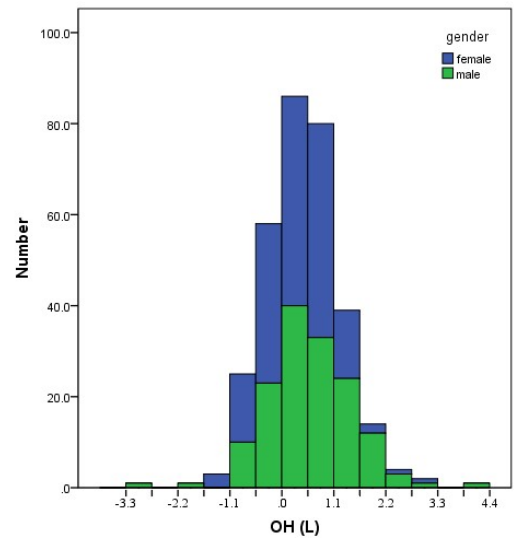

Fig. 1. Distribution of over-hydration $(\mathrm{OH})$ in healthy Chinese subjects

The data from the study subjects are shown in Table 1. The value of $\mathrm{OH}$ in male subjects is higher than in females $(t=2.692, p=0.007)$. The mean age, LTI, LTM, and BCM were significantly higher in the male subjects than in the females $(\mathrm{p}<0.001)$. However, the value of FTI $(t=-4.474, p<0.001)$ was significantly higher in females, but Fat $(t=-0.629, p=0.530)$ and $\mathrm{BCM}(t=-0.624, p=0.533)$ did not differ significantly between the two groups. The overall mean of the $\mathrm{PhA}$ value was $5.607 \pm 0.71^{\circ}$. A highly significant gender difference in the mean $\mathrm{PhA}$ value was observed (male versus female: $5.975 \pm 0.70^{\circ}$ versus $5.275 \pm 0.53^{\circ}, t=9.858, p<0.001$ ).

Table 1. Comparison of parameters derived from BCM between males and females.

\begin{tabular}{|c|c|c|c|c|c|}
\hline Characteristics & All $(n=314)$ & Male $(n=149)$ & Female $(\mathrm{n}=165)$ & $t$ & $p$ \\
\hline Age (years) & $45.701 \pm 13.13$ & $49.080 \pm 14.55$ & $42.649 \pm 10.88$ & 3.911 & $<0.001$ \\
\hline $\mathrm{OH}(\mathrm{L})$ & $0.379 \pm 0.81$ & $0.505 \pm 0.89$ & $0.266 \pm 0.71$ & 2.692 & 0.007 \\
\hline LTI $\left(\mathrm{kg} / \mathrm{m}^{2}\right)$ & $12.552 \pm 2.28$ & $14.233 \pm 1.83$ & $11.033 \pm 1.41$ & 17.231 & $<0.001$ \\
\hline FTI $\left(\mathrm{kg} / \mathrm{m}^{2}\right)$ & $11.698 \pm 3.55$ & $10.764 \pm 3.13$ & $12.542 \pm 3.70$ & -4.474 & $<0.001$ \\
\hline LTM (kg) & $34.292 \pm 8.15$ & $41.181 \pm 5.72$ & $28.072 \pm 3.91$ & 23.463 & $<0.001$ \\
\hline Fat (kg) & $23.225 \pm 7.06$ & $23.022 \pm 7.27$ & $23.409 \pm 6.88$ & -0.629 & 0.530 \\
\hline ATM (kg) & $31.604 \pm 9.61$ & $31.330 \pm 9.89$ & $31.850 \pm 9.37$ & -0.624 & 0.533 \\
\hline BCM (kg) & $18.542 \pm 5.35$ & $22.960 \pm 3.92$ & $14.552 \pm 2.65$ & 22.011 & $<0.001$ \\
\hline $\operatorname{PhA}\left({ }^{\circ}\right)$ & $5.607 \pm 0.71$ & $5.975 \pm 0.70$ & $5.275 \pm 0.53$ & 9.858 & $<0.001$ \\
\hline
\end{tabular}

Note: Variables are expressed as mean $\pm \mathrm{SD}$.

Abbreviations: OH, over-hydration; LTI, lean tissue index; FTI, fat tissue index; LTM, lean tissue mass; fat, lipid mass; ATM, adipose tissue mass; BCM, body cell mass; PhA, phase angle.

\subsection{Univariate Correlation Analysis}


In univariate analysis, age $(r=0.040, p=0.484)$ and LTI $(r=0.070, p=0.216)$ were not correlated to $\mathrm{OH}$ in the subjects $(p=0.484, p=0.216)$. However, FTI $(r=-0.276, p<0.001 ; r=-0.244, p<0.001)$, Fat $(r=-0.258, p=0.001 ; r=-$ $0.174, p=0.002)$, and ATM $(r=-0.258, p=0.001 ; r=-0.174, p=0.002)$ had a significantly negative correlation to $\mathrm{OH}$ in female and all subjects, while LTM $(r=0.140, p=0.013), \mathrm{BCM}(r=0.122, p=0.031)$ had a positive correlation in all subjects. There was also a significant correlation between $\mathrm{PhA}$ and $\mathrm{OH}$ in male, female, and all subjects $(r=-$ $0.634, p<0.001 ; r=-0.666, p<0.001 ; r=-0.484, p<0.001)$ (Table 2$)$.

Table 2. Univariate analysis of subject's characteristics in association with the $\mathrm{OH}$.

\begin{tabular}{|c|c|c|}
\hline \multirow{2}{*}{ Characteristics } & \multicolumn{2}{|c|}{$\mathrm{OH}$} \\
\hline & Correlation Coefficient & $p$-Value \\
\hline \multicolumn{3}{|l|}{ Age (years) } \\
\hline Female & 0.004 & 0.985 \\
\hline Male & 0.003 & 0.968 \\
\hline All & 0.040 & 0.484 \\
\hline \multicolumn{3}{|l|}{ LTI $(\mathrm{kg} / \mathrm{m} 2)$} \\
\hline Female & 0.102 & 0.191 \\
\hline Male & -0.150 & 0.068 \\
\hline All & 0.070 & 0.216 \\
\hline \multicolumn{3}{|l|}{ FTI (kg/m2) } \\
\hline Female & -0.276 & $<0.001$ \\
\hline Male & -0.163 & 0.047 \\
\hline All & -0.244 & $<0.001$ \\
\hline \multicolumn{3}{|l|}{ LTM (kg) } \\
\hline Female & 0.147 & 0.060 \\
\hline Male & -0.029 & 0.721 \\
\hline All & 0.140 & 0.013 \\
\hline \multicolumn{3}{|l|}{ Fat $(\mathrm{kg})$} \\
\hline Female & -0.258 & 0.001 \\
\hline Male & -0.100 & 0.224 \\
\hline All & -0.174 & 0.002 \\
\hline \multicolumn{3}{|l|}{$\mathbf{A T M}(\mathrm{kg})$} \\
\hline Female & -0.258 & 0.001 \\
\hline Male & -0.100 & 0.223 \\
\hline All & -0.174 & 0.002 \\
\hline \multicolumn{3}{|l|}{ BCM (kg) } \\
\hline Female & 0.132 & 0.090 \\
\hline Male & -0.064 & 0.437 \\
\hline All & 0.122 & 0.031 \\
\hline \multicolumn{3}{|l|}{$\operatorname{PhA}\left({ }^{\circ}\right)$} \\
\hline Female & -0.666 & $<0.001$ \\
\hline Male & -0.634 & $<0.001$ \\
\hline
\end{tabular}


Abbreviations: OH, over-hydration; LTI, lean tissue index; FTI, fat tissue index; LTM, lean tissue mass; Fat, lipid mass; ATM, adipose tissue mass; BCM, body cell mass; PhA, phase angle.
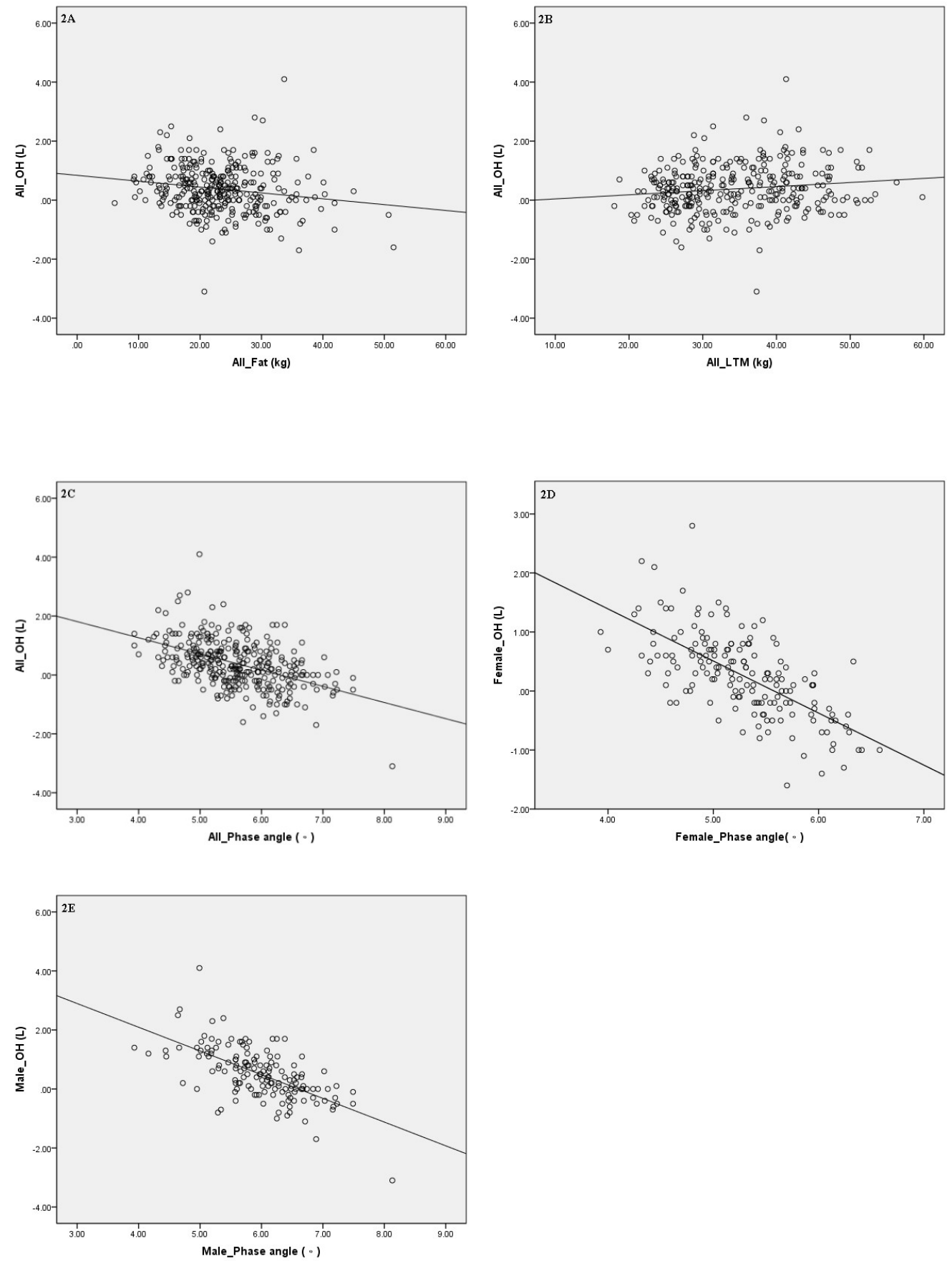

Figure 2. Pearson's correlation between $\mathrm{OH}$ and various parameters in different groups.

Abbreviations: OH, over-hydration; LTM, lean tissue mass; Fat, lipid mass; PhA, phase angle.

\subsection{Multiple Linear Regression Analysis}


Multiple linear regression analysis was performed using $\mathrm{OH}$ as the dependent variable and characteristics including age, gender, LTM, Fat, and PhA as independent variables, excluding FTI, ATM, and BCM due to collinearity. A significant regression equation was found $(\mathrm{F}=189.896, p<0.001)$ with an adjusted $\mathrm{R}^{2}$ of 0.755 . $\mathrm{PhA}$ $(\beta=-1.266,95 \% C I=-1.532 \sim-1.341, p<0.001)$, LTM $(\beta=0.987,95 \% C I=0.086 \sim 0.109, p<0.001)$, age $(\beta=-0.307$, 95\% $C I=-0.023 \sim-0.015), p<0.001)$ were independently associated with $\mathrm{OH}$, but gender $(\beta=-0.051,95 \% C I=-$ $0.245 \sim 0.079, p=0.315)$ and Fat $(\beta=-0.049,95 \% C I=-0.012 \sim 0.001, p=0.089)$ were not independently associated (Table 3).

Table 3. Multiple linear regression analysis of variables influencing the $\mathrm{OH}$

\begin{tabular}{|c|c|c|c|c|}
\hline & \multicolumn{2}{|c|}{ Unstandardized Coefficients } & $\begin{array}{l}\text { Standardized } \\
\text { Coefficients }\end{array}$ & \multirow{2}{*}{$p$-value } \\
\hline & Beta Coefficient & Standard Error & $\beta$ & \\
\hline Constant & 6.203 & 0.378 & -- & $<0.001$ \\
\hline Age (years) & -0.019 & 0.002 & -0.307 & $<0.001$ \\
\hline Gender & -0.083 & 0.082 & -0.051 & 0.315 \\
\hline Fat $(\mathrm{kg})$ & -0.006 & 0.003 & -0.049 & 0.089 \\
\hline LTM (kg) & 0.098 & 0.006 & 0.987 & $<0.001$ \\
\hline $\operatorname{PhA}\left({ }^{\circ}\right)$ & -1.437 & 0.048 & -1.266 & $<0.001$ \\
\hline
\end{tabular}

Abbreviations: OH, over-hydration; LTM, lean tissue mass; Fat, lipid mass; PhA, phase angle.

\section{Discussion}

The main findings of the study were as follows: 1) $78.7 \%$ of individuals had values equivalent to the standard values of healthy Caucasian subjects in foreign countries $(-1.1 \sim 1.1 \mathrm{~L}) .2)$ There was a significant correlation between $\mathrm{PhA}(p<0.001)$ and $\mathrm{OH}$ in male, female, and all subjects. 3) In multivariate linear regression analysis age, LTM, and $\mathrm{PhA}$ were independent predictors of $\mathrm{OH}$, and $\mathrm{PhA}$ was the most important predictor of $\mathrm{OH}$.

We found that $\mathrm{OH}$ of healthy Chinese subjects (78.7\%, Figure 1) was equivalent to the standard value of healthy subjects in foreign countries $(-1.1 \sim 1.1 \mathrm{~L})$. According to the brochure of the BCM the reference value of $\mathrm{OH}$ is represented by the $10^{\text {th }}$ to $90^{\text {th }}$ percentile for healthy Caucasian subjects. In a study of healthy Japanese, $76.3 \%$ of the subjects were within the standard value. ${ }^{[8]}$ As such, the use of this measure was thought to be equally suitable for Asians. However, there may be small differences in $\mathrm{OH}$ level among ethnic groups, by dietary habits and regions. Therefore, in the future, it will be necessary for us to investigate reference values of healthy Chinese for better application of $\mathrm{BCM}$ to clinical practice.

It is known that males have more lean tissue, whereas females have higher fat percentages ${ }^{\left[{ }^{[, 10]}\right.}$ LTI and LTM obtained with the BCM correspond to lean tissue. Fat, FTI and ATM that were obtained with the BCM correspond to adipose tissue. In our study, we also found that the LTI and LTM of males were significantly higher than those of females, while the FTI of females was significantly higher than that of males. But Fat and ATM did not differ significantly between the male and female subjects. In addition to the small size of the study population or racial 
differences, another potential reason for the results might be that Fat and ATM were not adjusted for height. Therefore, more studies will be needed to elucidate the differences of body composition between healthy Chinese males and females.

Many studies have reported relationships between body composition and hydration status. ${ }^{[1-14]}$ Adipose tissue contains about $10 \%$ water, while muscle contains about $75 \%$ water. In our study, we found that adipose tissue (FTI, Fat, and ATM) had a weakly negative correlation with $\mathrm{OH}$ in females and all subjects (Table 2) by univariate analysis. The association between adipose tissue and $\mathrm{OH}$ was abolished when adding age, gender, LTM, and PhA to the multivariate linear regression analysis (Table 3), which suggested that there may be no correlation between the adipose tissue and $\mathrm{OH}$. Simultaneously, we found that LTI was not associated with $\mathrm{OH}$ in univariate analysis (Table 2), while LTM had a positive correlation to $\mathrm{OH}$ in all subjects on univariate or multivariate analysis (Table 2, Table 3), which indicated that lean tissue was one of the most important predictors of $\mathrm{OH}$. Consistent with the findings of previous studies, we found that lean tissue contained more water than adipose tissue. ${ }^{[15]}$ Importantly, we found that PhA was highly significant in males, females, and all subjects in the univariate analysis (Table 2, Figure 2C, 2D, 2E). Furthermore it was a significant predictor of $\mathrm{OH}$ in multiple linear regression analyses, $\mathrm{PhA}$ was the most important predictor of $\mathrm{OH}$ according to standardized coefficient in regression equation (Table 3 ). As far as we know, our study is the first to explore the correlation between the $\mathrm{PhA}$ and $\mathrm{OH}$ in healthy individuals.

The topic of $\mathrm{OH}$ calculation in the healthy Chinese people is important in clinical practice because it will guide adjustment of dry weight in dialysis patients. Recent studies have shown that nutritional status was inversely associated with $\mathrm{OH}$ in patients with chronic kidney disease or hemodialysis. ${ }^{13,14]}$ LTM and PhA could be used as markers to reflect nutritional status. ${ }^{[16-19]}$ There has been growing interest in the use of PhA as a surrogate for LTM in the assessment of nutritional status, because raw bioimpedance is not influenced by hydration status. ${ }^{[20,21]}$ Based on our results, nutritional status (and especially $\mathrm{PhA}$ ) should be considered when determining specific ultrafiltration volume in hemodialysis patients, in order to decrease adverse events caused by excessive or insufficient ultrafiltration. One limitation of our study was that it was a cross-sectional observational study that included a relatively small number of subjects, and further studies in larger populations will be needed.

In conclusion, age, LTM and $\mathrm{PhA}$ were independent predictors for $\mathrm{OH}$, and $\mathrm{PhA}$ was the most important predictor in the healthy Chinese people. In the future, use of $\mathrm{PhA}$ to titrate dry weight may benefit hemodialysis patients with malnutrition.

\section{References}

[1] Hung SC, Lai YS, Kuo KL, Tarng DC. Volume overload and adverse outcomes in chronic kidney disease: clinical observational and animal studies. J Am Heart Assoc. 2015, 4, e001918. DOI:10.1161/JAHA.115.001918

[2] Shotan A, Dacca S, Shochat M, Kazatsker M, Blondheim DS, Meisel S. Fluid overload contributing to heart failure. Nephrol Dial Transplant. 2005,20, Suppl 7: vii24-7.DOI:10.1093/ndt/gfh1103

[3] Palmer BF, Henrich WL. Recent advances in the prevention and management of intradialytic hypotension. J Am Soc Nephrol. 2008,19, 8-11.DOI:10.1681/ASN.2007091006

[4] Berger D, Takala J. Hypotension and hypovolemia during hemodialysis: is the usual suspect innocent. Crit Care. 2016, 20, 140. DOI:10.1186/s13054-016-1307-4

[5] Rosenberger J, Kissova V, Majernikova M, Straussova Z, Boldizsar J. Body composition monitor assessing malnutrition in the hemodialysis population independently predicts mortality. J Ren Nutr. 2014, 24, 172-6. DOI:10.1053/j.jrn.2014.01.002 
[6] Keane DF, Baxter P, Lindley E, et al. The Body Composition Monitor: a flexible tool for routine fluid management across the haemodialysis population. Biomed Phys Eng Express. 2017., 3,pii: 035017.DOI:10.1088/2057-1976/aa6f45

[7] Keane DF, Bowra K, Kearney K, Lindley E. Use of the Body Composition Monitor for Fluid Status Measurements in Elderly Malnourished Subjects. ASAIO J. 2017, 63, 507-511. DOI:10.1097/MAT.0000000000000508

[8] Nakagawa H, Sato Y, Toshimori H, Fujimoto S. Evaluation of a new bio-impedance spectroscopy device in healthy Japanese. Biomed Mater Eng. 2015, 26, 97-102. DOI: 10.3233/BME-151553

[9] Blaak E. Gender differences in fat metabolism. Curr Opin Clin Nutr Metab Care. 2001,4, 499-502.

[10] Bredella MA. Sex Differences in Body Composition. Adv Exp Med Biol. 2017,1043, 9-27. DOI: 10.1007/978-3-319-70178-3_2

[11] Scharfetter H;Brunner P;Mayer M;Brandstätter B;Hinghofer-Szalkay H. Fat and hydration monitoring by abdominal bioimpedance analysis: data interpretation by hierarchical electrical modeling. IEEE Trans Biomed Eng.2005, 52, 975-82. DOI:10.1109/TBME.2005.846733

[12] Pifer TB, McCullough KP, Port FK, et al. Mortality risk in hemodialysis patients and changes in nutritional indicators: DOPPS. Kidney Int. 2002, 62, 2238-45. DOI:10.1046/j.1523-1755.2002.00658.x

[13] Lee JE, Jo IY, Lee SM, et al. Comparison of hydration and nutritional status between young and elderly hemodialysis patients through bioimpedance analysis. Clin Interv Aging. 2015, 10, 1327-34. DOI:10.2147/CIA.S86229

[14] MJE D, Konings C, Canaud B, et al. Interactions Between Malnutrition, Inflammation, and Fluid Overload and Their Associations With Survival in Prevalent Hemodialysis Patients. J Ren Nutr. 2018, 28, 435-444. DOI:10.1093/ndt/gfq588

[15] Wang J, Pierson RN. Disparate hydration of adipose and lean tissue require a new model for body water distribution in man. J Nutr. 1976, 106(12), 1687-93.DOI: 10.1093/jn/106.12.1687

[16] Lukaski HC, Kyle UG, Kondrup J. Assessment of adult malnutrition and prognosis with bioelectrical impedance analysis: phase angle and impedance ratio. Curr Opin Clin Nutr Metab Care. 2017, 20, 330-339. DOI:10.1097/MCO.0000000000000387

[17] Kyle UG, Genton L, Pichard C. Low phase angle determined by bioelectrical impedance analysis is associated with malnutrition and nutritional risk at hospital admission. Clin Nutr. 2013, 32, 2949.DOI:10.1016/j.clnu.2012.08.001

[18] Valtuille R, Casos ME, Fernandez EA, Guinsburg A, Marelli C. Nutritional Markers and Body Composition in Hemodialysis Patients. Int Sch Res Notices. 2015, 2015, 695263.DOI: $10.1155 / 2015 / 695263$

[19] Aatif T, Hassani K, Alayoud A, et al. Parameters to assess nutritional status in a Moroccan hemodialysis cohort. Arab J Nephrol Transplant. 2013, 6, 89-97.

[20] Mulasi U, Kuchnia AJ, Cole AJ, Earthman CP. Bioimpedance at the bedside: current applications, limitations, and opportunities. Nutr Clin Pract. 2015, 30, 180-93. DOI;10.1177/0884533614568155

[21] Tsai YC, Tsai JC, Chen SC, et al. Association of fluid overload with kidney disease progression in advanced CKD: a prospective cohort study. Am J Kidney Dis. 2014, 63, 68-75.

DOI:10.1053/j.ajkd.2013.06.011 